\title{
Paradigm as a Critical Analysis Tool in Education/Special Education
}

\author{
Amadeusz Krause ${ }^{1}$ \\ ${ }^{1}$ University of Gdansk, Poland
}

HOW TO CITE:

Krause, A. (2021).

Paradigm as a Critical

Analysis Tool

in Education/Special Education.

International Journal

of Special Education,

36(1), 49-58

CORRESPONDING AUTHOR:

Amadeusz Krause;

adkraus@poczta.onet.pl

DOI:

https://doi.org/10.52291/

ijse.2021.36.5

COPYRIGHT STATEMENT:

Copyright: (C) 2021 Authors.

Open access publication under the terms and conditions of the Creative Commons

Attribution (CC BY)

license (http://creativecommons.

org/licenses/by/4.0/).

\begin{abstract}
Familiarity with the concept and the essence of a paradigm allows for analysing a text and assessing the research intention of its author. In this mode, one can trace the correctness of theoretical and conceptual deduction in publications, the mode of combining paradigms by other researchers, including unauthorised borrowings and interpretations. Such knowledge is also necessary to plan research projects. The text draws attention to the problem of incommensurability of paradigms, errors in their application and difficulties with interpreting publications devoid of paradigmatic declarations. The author of the paper highlights the modes and risks of using several years of theoretical achievements of education and special education.
\end{abstract}

Keywords: paradigm, paradigmatic awareness, knowledge construction, critical text analysis 


\section{INTRODUCTION}

To understand the significance of a paradigm in critical academic analysis, it is necessary to adopt a specific conceptual category to understand the attributes of paradigm and to indicate the mode of their use. Obviously, one may venture a question: why does a researcher of educational science need such knowledge? The answer lies in the nature of building knowledge in education. It is a standard that for the needs of studies, theoretical issues are prepared, relying on the accomplishments of researchers over several decades. Oftentimes, quotations and references are purely thematic, and provided without distinguishing the period to which they refer, the methods that were used for data compilation, the data that the contemporary researchers relied on or the premises that accompanied their interpretations and the social and cultural context in which they were adopted. Such raw transfer of interpretations may lead to adoption of erroneous theoretical premises and in consequence, to bad methodological choices, rendering a research project doubtful or even absurd. In this sense, understanding the contexts of knowledge creation, as well as its paradigmatic nature, not only facilitates its analysis, but also protects, in a certain manner, from adopting incorrect assumptions in the designed projects.

\section{Paradigm:}

\section{Why Are Problems with the Concept So Significant?}

Without doubt, this concept, which has become so popular in the modern science, has its source in the perspective of philosophical analyses about building knowledge and development of science. Insofar as the priority of applying this term in philosophy may be subject to a discussion, it must be acknowledged that the works of Kuhn, in particular the "Structure of Scientific Revolutions" (Kuhn, 2001), have contributed to its popularisation.

In Kuhn's first works, the structure of the paradigm related to the development of science assumed existence of a certain academic community sharing a view with the same significance and materiality, which not only distinguished them as a group, but also designated the principles of research conduct, allowed for diversification and exclusion of other views, described academic progress and its stages (first original publication, Kuhn 1962). Science, according to Kuhn, develops in a two-track mode, in the period of the so-called standard development, as long as it is capable of explaining the existing scientific puzzles, and through scientific revolutions in case it fails to tackle the- se puzzles applying the current knowledge. Kuhn made the paradigm the key category of change. Since the very beginning, this category has been accused of ambiguity, also due to the fact that Kuhn used it inconsistently in several dozen meanings (cf. Masterman, 1970, p. 61). An example may be the aforementioned "Structure", where the researchers of T. Kuhn's works distinguished over 20 meanings of a paradigm.

Later works of Kuhn are also problematic: the concept of paradigm was transformed, inter alia under the impact of a critical discussion about the model of science development. The discussion had continued until the author replaced his concept with the category of an exemplar and a disciplinary matrix. In this approach, the sensu stricto paradigm would be an exemplar, a specific scientific accomplishment, a discovery, a specific puzzlesolving. On the other hand, a paradigm in a broader meaning, sensu largo, would be a set of ordered elements of various types, determining a common standpoint for the scientists of a given discipline, basic claims, concepts and theories (Kuhn, Postscriptum.... 2001).

The concept of the matrix and the exemplar are well explained in educational science by broader paradigms, of greater scope, e.g. disciplinary or inter-disciplinary (humanistic paradigm) and narrower ones, e.g. sub-disciplinary (subjective, rehabilitative, emancipatory, etc.). Nowadays, there is a dominant view in education that:

"A paradigm is a set of concepts, theories and methodological premises, accepted in a given historical period by scientists as scientific and adequately explaining the reality..."

(Klus-Stańska, 2018, p. 38)

Some of Kuhn's original assumptions about the characteristics of paradigm posed a problem for social sciences and humanities. In "Structure", Kuhn himself had doubts about paradigms in social sciences claiming:

"it remains an open question what parts of social science have yet acquired such paradigms at all. History suggests that the road to a firm research consensus is extraordinarily arduous."

(Kuhn, 2001, p. 38)

The premise of mutual preclusion of paradigms was the primary problem for social sciences. In the first version, Kuhn assumed that a new discovery, typical for experimental sciences, is scientifically confirmed and accepted by the ever-growing community of scientists which, in 
turn, leads to the dominance of a new paradigm. This condition seemed difficult to meet in social sciences, including educational science, where multiplicity of concepts, theories and stances functioning in parallel, would render it a non-paradigmatic science. Nevertheless, in the course of time, along with admitting the possibility of existence of multi-paradigm disciplines, this view subsided. Kuhn himself, in his later works, e.g. in "The Road Since Structure”, no longer excluded such possibility (Kuhn, 2003).

There are many reasons to consider education a multi -paradigm discipline. The main one follows from the sole nature of education, where cultural and social meanings are subject to negotiations, where unanimity is replaced by interpretations and objectivity is not the only way of cognition. Multi-paradigmatic nature in this case means that paradigms may be mutually exclusive, that some are replaced by new ones, some are abandoned, and others begin to dominate; however, it is assumed that some of them remain in parallel with respect to the new ones or are positioned anew in the hierarchy. A peculiar map of paradigms is developed, not only with a broader and narrower range, but also featuring competitive paradigms, disputed and alternative ones.

\section{Pedagogy As a Multi-Paradigm Discipline}

Researchers' long-lasting discussion about paradigms in education does not entail that the scope of application of this concept has been unified. Multiple standpoints with respect to the nature and the essence of paradigms are still dominant in the works devoted to education, which may pose an interpretative difficulty for the recipient as to what the author had in mind and which theoretical assumptions were adopted.

Without delving any further into the philosophical debate on the accuracy of the concept of paradigm here (those interested will easily find such discussions in the works published also in Poland), I would like to draw attention to three issues that are useful, in my opinion, for every education practitioner who makes use of works of other researchers. It is the issue of handling the ambiguity of the term paradigm, the significance of using it from the point of view of development of social sciences and the manner in which it may become useful for a critical analysis in such discipline as education.

The first issue of defining a paradigm may evoke dilemmas, in particular among young researchers. The multiplicity and the ambiguity of the concept applied in literature is bewildering and the authority of well-known researchers and adoption of frequently contrasting stances makes a just choice nearly impossible. The difficulty with making the right choice may be additionally aggravated by the diversified attitudes to the paradigm category among the education practitioners who either adopt the original or the secondary version of Kuhn, limit its scope and meaning, completely change its content or even reject it entirely. In other words, there may be situations when a publication that is under analysis makes use of the term paradigm, but has little to do with how it is understood in science.

This issue becomes even more complex as adoption of a specific meaning of paradigm has consequences not only with respect to the content and the range of application of the term, but also the vision of development of science in the discipline that is practised, the essence of relations of the models, the theories and concepts in such discipline or the dimension of methodological (also theoretical) ordering. "Paradigmatic identification," says Łopatkowska
"requires not only proper discernment of the com-
plexity of modern pedagogy, but also knowledge
about the paradigm as an epistemological construct,
the elements comprising it and the consequences
that result from founding research activities on it."
(Eopatkowska, 2017, p. 399)

Whilst clarifying the consequences of understanding paradigms with the examples from the area of education, attention should be drawn to a typical for many of its sub-disciplines (also for special education) appropriation of such category in the form of a postulate or as forms of practical educational activities. An example is provided by the works of Obuchowska and Twardowski, where the family cooperation paradigm or the positive thinking paradigm is mentioned (Obuchowska, 1987; Twardowski, 2004). This approach to the paradigm that has little to do with the original is only a mode of using the term to provide the promoted theory and postulate of a higher rank. It does not have any direct significance for the mode of overviewing the examined reality and for searching for a meta-theoretical perspective, yet it may emphasise the significance of educational actions in the personal theory of a researcher. In its consequences as part of the sub-discipline, it may designate certain directions of actions or emphasise their significance with respect to others, which may result in certain hierarchisation of studies. The case is similar with emphasising the significance of a child's subjectivity via the category of a paradigm, which makes it a stream of research signi- 
ficant both in school education and in special education. In this case, it is difficult to talk about the paradigmatic awareness of persons using this concept in this manner, yet there is a material emphasis on the significance of the phenomenon for the academic discipline, which also constitutes one of the features of a paradigm.

A researcher, making use of such sources, has to be aware that in an academic discussion such range of use of the term does not entail that we are actually dealing with a paradigm. For example, humanistic, constructivist and subjective paradigms, as well as support for cooperation with the family paradigm in education should not be enumerated next to each other as in this way, categories with various meanings are combined, showing not only misunderstanding of this conceptual category, but also misleading the recipient.

On the other hand, understanding the paradigm as a methodological model seems to be much less disputable. This category, most commonly encountered in education, is understood both in a narrow sense, i.e. exclusively as conducting a research procedure, as well as in a broader context, i.e. as a determination of the modes of understanding the studied reality. Many studies available in education allow for learning the level of the researcher's paradigmatic awareness through such methodological approach, which is expressed in the perception of consequences of own methodological path. Literature also features works showing low awareness of the applied methodological paradigm. Examples include works where the researcher, declaring a quality paradigm and data collected in such convention, attempts to objectify the results of own studies.

Meta-theoretical or epistemological approach to a paradigm is not uniform or even popular among education practitioners. However, its significance may be perceived through the consequences of Kuhn's structure of the exemplar and the disciplinary matrix. Such broad or narrow understanding of a paradigm is particularly significant for multi-paradigm sciences (if we agree that such sciences exist), as it allows for creation of a peculiar map of paradigms or a paradigm hierarchy, which is of fundamental significance for the understanding of the modern education (cf. Śliwerski, 2009). Such approach facilitates the category's transfer to the sub-disciplines of education which, in compliance with the disciplinary matrix, make up paradigms with a narrower meaning, types of exemplars that bring the communities together, including handling of disability-related issues.

An illustration is provided by a humanistic paradigm, reflected in the sub-disciplines of education through the category of emancipation, subjectivity, integration, normalisation, etc. Even though theoretical categories in education will never be as expressive as in experimental sciences and their identification may raise controversies, their significance for showing the links of the sub-discipline with the main currents of meta-theory is not to be underestimated.

An example is not only the development of the last 20 years of special education, but also social rehabilitation, didactics, school counselling, special methodologies and others, where the majority of new cognitive impulses originate from beyond "own" sub-disciplinary theoretical background. Let us illustrate it with the current situation of a disabled child in a general education school. In the narrow perspective of the sub-discipline, we may examine the efficiency of teaching in a school of such type, peer relations in a class, efficiency of the child's rehabilitation and scope of the necessary support, satisfaction of special educational needs. When we venture beyond the "special education", towards cultural theories, critical sociological, social and psychological studies, we will notice much more, e.g. the oppressive role of institutions originating from the concept of Foucault (1975), the concept of stigma deriving from the concept of Goffman (1975), the concept of the Other in the approach of Bauman (1995), the Pedagogy of the Oppressed of Freire (1970) and many other theories, which special education practitioners may use to describe such phenomenon.

\section{Why Is Paradigm Needed in Education?}

In order to make use of non-sub-disciplinary science and to participate in a common scientific discourse, a mutual understanding of researchers is needed, at least via concept categories, clarity of the adopted premises and consistency of arguments. In Kuhn's approach, the understanding of studies requires consistency of the matrix and the paradigm's exemplar, i.e. creation of a narrative and arguing within the same paradigm. The awareness of such consistency is growing in education, year by year, which results in the criticism of fragmentary education, deprived of the understanding of the context of the examined phenomenon. It is still possible to find works that are "isolated" in the disciplinary sense in the Polish educational science, yet these cases are rather rare. It seems that along with the popularisation of the socio-cultural model of disability and its consequences, special education practitioners make more frequent use of the accomplishments of similar disciplines than of other sub-disciplines of education. 
Obviously, awareness of the compliance of the exemplar and the discipline matrix will not protect many researchers from making ostensible or misguided links. The fact that someone declares operation within the framework of humanistic or interpretative paradigm does not mean that this is really the case. However, this issue is more complex and will be handled in the further part of this study.

Popularity of the category of paradigm in education entails not only its significance in the context of identification of changes in education, but also the power of the concept as such. Łopatkowska justly notes after a detailed analysis of applications of the concept in education that the term may be replaced by other accepted and less troublesome terms such as: model, view, theory, postulate, direction of studies, etc. (Łopatkowska, 2017, p. 394). Therefore, why has it not been discarded? I believe that the advantage of the paradigm in education is the strength of this concept. This is what the education researchers needed not only to distinguish one scientific model from another one, but also to indicate its significance, superiority, validity, advantage over others, etc.

To sum up this part of the discussion, the use of paradigms as a tool of critical analysis not only requires understanding of paradigms and their meaning in education, but also their attributes such as, for example, incommensurability, modes of expiry and principles of concomitance.

\section{PARADIGM AS A TOOL OF CRITICAL ANALYSIS}

\section{Works Without Paradigmatic Declaration}

Independently from multiple approaches to the paradigm in the social sciences and complications resulting from a transition of this category from exact sciences, it may be assumed that education features works with clear paradigmatic declarations with the use of the category of paradigm and works without such declaration, often with an unspecified paradigm or works with an unrealised paradigm.

Let us start with a situation when the researcher does not position his/ her studies in any specific paradigm, yet such paradigm is, from today's perspective, easy to identify. These are, in majority, works from a period when the category of paradigm was not used, but it can be clearly recognised on account of the current studies in which they were created. An example is provided by the studies which are described with the use of an objectivist paradigm. They include the authors' certainty with respect to scientific cognition of the world, discovery of facts and regularities, confirmation or rejection of the proposed theses and hypotheses. In the present-day pedagogical studies, we can find critical analyses of this cognitive path, often dubbed naïve scientism. We also tend to look at the results of such studies with a certain distance from the perspective of the constructivist and interpretative paradigm, assuming non-contextual inscrutability of the social world. Being aware of the context in which knowledge is created, we do not accept it as a scientific axiom or, even more, as a thoughtless starting point of own research project.

However, some authors fail to notice it. Building their methodological projects in the 21 st century, they try to find a justification for them in the works written several decades ago. Oftentimes, the presented results of other researchers are quoted only in fragments, without specifying the mode and the situation in which the study was performed. The authors, quoting studies in such "raw" manner, lose their social context. In the Polish pedagogy and society which underwent a system transformation in the 1990s, such "unconscious time travels" are methodologically very dangerous. An example is provided by numerous studies on the integration situation of persons with disabilities, which are found in special education publications. It is known from modern studies on disability that the assessment of the level or readiness for social integration without the social and cultural context may be useless. Comparing, for example, the degree of educational integration over the years and concluding, on this basis, about the condition (openness) of special education in Poland may lead to absurd conclusions that the special education teachers are responsible for the lack of progress of integrated education.

The basic trap of failing to notice a paradigm in a publication lies in the non-contextual understanding and reliance on the knowledge created by predecessors (cf. Krause, 2014). Even if it is assumed that the education researchers in the last century did not distinguish paradigms, it does not mean that they did not create knowledge in a specific paradigm or that they were not under its impact. In consequence, today's researcher, when preparing his/ her research project in typical pedagogical areas, e.g. educational functioning of a family, child subjectivity issues, emancipation or disability, cannot thoughtlessly rely on the theses and results of studies published several decades ago without an attempt at defining the paradigm in which such studies were created. 
Kuhn describes the non-contextual references to researchers in the scientific tradition as follows:

"Partly by selection and partly by distortion, the scientists of early ages are implicitly represented as having worked upon the same set of fixed problems and in accordance with the same set of fixed canons that the most recent revolution in scientific theory and method has made seem scientific. No wonder that textbooks and the historical tradition they imply have to be rewritten after each scientific revolution.”

(Kuhn 2001, p. 240)

The situation described by Kuhn is also valid in a situation when we are convinced about remaining within the same paradigm and fail to notice the necessity of translating its cultural and social context. An example is provided by the emancipatory paradigm that is in use. The perspective of the present-day situation of a small child and the perspective of women from the 1950s, fighting for their voting rights, is different in such paradigm. The case is similar with the use of Goffman's stigma to assess the present-day situation of persons with disabilities, without paying attention to the fact that Goffman (1975) built his theory in the context of racial discrimination; or the Foucault's vision of an institution of a psychiatric hospital overlooking the present-day mechanism of social discipline. All these theories, which many researchers believe to be the sources of paradigms, should be treated with historical distance and translated to the modern context and language. Obviously, they may and should be used, in particular with respect to the identification of mechanisms described by their authors, yet one cannot thoughtlessly translate their interpretations, overlooking the modern socio-cultural context.

The situation of absence of a paradigmatic declaration also refers to works written today, where the author fails to see the necessity of referring to any changes, and the paper is written as if no differing paradigms were present. Unfortunately, this phenomenon still persists, not only among young academics. An example is provided by a monographic study entitled "Wartości w przystosowaniu osób niepełnosprawnych" ("Values in Adjustment of Persons with Disabilities”) (Korczyński, 2009). In the theoretical justification for his work, the author makes free references to several decades of pedagogy, psychology and sociology, spanning the period from the 1970s to 2000s. It is not known which paradigm is the starting point or what the premises are on which the methodological declarations are built; nevertheless, this does not stop the author from putting forward some strong theses such as:

"Persons with disabilities are the same as others, yet their disability results in changes in the structure and functioning of their bodies, psyche and behaviour."

(2009, p. 10)

From the point of view of scientific assessment, the work is not only a-paradigmatic, but in the context of the image of a person with disability, it is detrimental.

The lack of a paradigmatic declaration and the mode in which the author uses individual concepts and hitherto knowledge may tell us a lot about the quality of the analysed work, its theoretical and research premises, as well as the value of the performed studies.

\section{Works With Paradigmatic Declaration}

Let us move on to the second group of works which are provided with a clear paradigmatic declaration. Here, the critical analysis may encompass three possibilities. The first one is related to the use of the paradigm category, the second one to the acceptance or rejection of its attributes (e.g. range, incommensurability, hierarchy, etc.), whereas the third one to a broader analysis of the pedagogical phenomenon with respect to a specific exemplar or disciplinary matrix.

In the context of the first possibility, it is obvious that a mere approach to the paradigm by individual researchers offers a significant potential for the evaluation of scientific projects. By being aware of the mechanisms and consequences of adopting a paradigm, we may look at the projects from the perspective of concepts that were used, their premises, interpretations or potential inconsistencies.

I will use an example from the sub-discipline that I am most familiar with, namely special education, i.e. the approach to the paradigm presented by Obuchowska, which has already been quoted here $(1987$, p. 29$)$. The author distinguishes a number of paradigms, for example a self-revalidation paradigm, a paradigm of helping the helper, a paradigm of positive orientation, a biographic and subjective paradigm. Some of them have the form of postulates, others are meant to emphasise key issues. The author divides them into present and absent in special education, whereas their presentation, according to her, is meant to induce reflection and to designate directions of aligning actions to the changing reality. 
Without going into a discussion whether the categories indicated by Obuchowska are paradigms in the strict sense or not, identification of meaning that the author wanted to communicate is important for special education practitioners. By being aware of what a paradigm is and what it is not, we can notice the postulative and diagnostic nature of a study, without however providing it with a status of a disciplinary exemplar or a disciplinary matrix that unites the community of special education practitioners. We know that these are the theses of the author which rather indicate the practical problems in educational activities, where the category of a paradigm is used, to stress the significance or potentially the superiority of the discussed issues.

However, the use of Obuchowska's postulates as disciplinary exemplars of special education leads a number of researchers to an erroneous belief about the direction in which the modern science in this sub-discipline is constructed. An example of such misunderstanding and combination of numerous different categories can be found in the work of Stefańska (in any case quite good in the empirical section) (2018, p. 105). In the theoretical assumptions of the paper, the author defines the modern concepts of special education as paradigms formulated by Twardowski, e.g. the paradigm of positive thinking and orientation or the paradigm of helping the helper. However, these are not paradigms and they are not even concepts in the epistemological sense. These pedagogical postulates do not form a tendency in the development of special education, they are not axioms agreed on in the milieu of academics and they do not form a part of the leading academic categories of this sub-discipline.

Whilst making use of a paradigm understood in compliance with a disciplinary exemplar in a critical analysis, acknowledged by the majority of researchers from a given discipline, we must be aware of the features of a paradigm and its consequences. In the clarification, I will make use of the phenomenon of paradigmatic incommensurability indicated by T. Kuhn, i.e. the untranslatability of the old theories to the language of a new paradigm (cf. Krause, 2014, p. 33). However, this phenomenon will be viewed more extensively, in the context of the lexical resources that are used, i.e. the absence of a possibility of transferring certain linguistic meanings from one paradigm to the other.

\footnotetext{
"Individual paradigms," claims Klus-Stańska "have a language that is typical for them, which forms one of the important instruments of their identification, as it defines the paradigmatic iden-
}

tity of theories. (...) The language of a paradigm comprises, first of all, the lexical resources (typical terminology, key terms, frequently used phrases) and the style of argument. (...) Apart from the dominant language, which comprises a set of typical terms, the absence of certain concepts is significant for recognition of a paradigm. These "white spots", which form an area of excluded lexicon, show what is rejected in a paradigm as non-academic, and what is least insignificant, marginal or just a minor anomaly."

(2018, p. 54)

The differences in lexical resources are best illustrated by two most often occurring methodological paradigms, objectivist, often called the quantity paradigm and interpretative, also known as the quality paradigm. Adoption of one of these paradigms not only entails a specific nature of studies, i.e. measurement or interpretation, but also adoption of its language and meanings, i.e. forms and contents of research premises and presentation of results. A frequent error often consists in simplified thinking about a paradigm on the level of a method or the size of a study sample, overlooking the ontological and epistemological premises with respect to the cognition of the nature of the social and cultural world. It sometimes seems that in some pedagogical works the decision about a research paradigm is made not after the analysis of what is going to be studied, but what sample size can be reached. In extreme cases, the declarations on adoption of a quality paradigm are accompanied by quantity-related research problems and their interpretations.

An example is a Ph.D. thesis reviewed by me, where the author, examining the efficiency of music therapy techniques, performs measurements in a group of eight persons, interpreting the results in a quantitative form (such as, e.g., "improvement was recorded in six cases") and verifying hypotheses in numbers. Interestingly, the author, being aware of the difficulties of paradigmatic triangulation of individualistic (as she calls them) studies, makes breakneck attempts at generalising the received results. Among others, she writes that in spite of such limitations (i.e. the quality paradigm, AK), she "wanted to compare the results of both groups in order to find out if there was a difference between the groups and the applied methods (...)."

When evaluating or making use of a paper with a specific methodological paradigm, attention should be drawn not only to its final theses, but to the consistency of the researcher, starting with the nature of examining a specific 
phenomenon, through the language of assumptions and interpretations, up to the conclusions that were generated based on the collected material. The same mechanism refers to the construction of own research projects.

The broadest range of paradigm use in a critical analysis is the overview of a specific pedagogical phenomenon in its light. Klus-Stańska, when characterising perception of various phenomena at school, concludes that:

“(...) a paradigmatic difference means that the same facts are something different in the world of different paradigms (...). The same activities which, in the perspective of one paradigm, constitute teaching that is conducive to learning, in the light of another one, do not have much in common with learning, and may even be assessed as factors hindering the cognitive activity of pupils. What a representative of one paradigm believes to be the knowledge about the world, a representative of another one views as an arbitrarily dominant version of an image of reality."

(2018, p. 43)

The above means that whilst making use of the characteristics of a given phenomenon or an educational situation prepared by other researchers, we have to be aware of the paradigmatic perspective of such overview. Without it, there is a risk of indicating premises or attributes that are mutually exclusive, leading to conclusions contradictory to the intention of the performed study.

I will illustrate it with two examples. The first and the simplest one is the commonly used category of a standard, as a concept applied in didactics, social pedagogy, rehabilitation pedagogy, development psychology etc. In the objectivist paradigm, we can look at it through measurement or description of meeting the standard or failure to do so. The consequences of a failure will primarily have individual nature, i.e. failure to fit within the standard, a deviation from the standard, a deficiency, a development deficiency, an aberration, social maladjustment, etc. Praxeology relying on such paradigm, will aim at accomplishing the standard via rehabilitation, therapy, re-adaptation, adaptation, etc. Compliance with the standard will be, in certain cases, perceived as normalcy or even social benefit, the goal of educational and care activities.

On the other hand, in the constructivist paradigm, the standard will be an effect of socio-cultural determinations of disciplinary nature. In this approach, the standard may be an excluding and stigmatising mechanism, whereas the pedagogical activities will not be aimed at adjusting the individual to the standard, but at "expanding" the category of the standard. From this perspective, mere rehabilitation with the aim of correct social adaptation may be defined as an oppressive activity towards a person with disabilities.

Another example in the area of special education is integration of persons with disabilities. This is a phenomenon frequently described and studied through various theoretical perspectives. Polish literature presents approaches to integration from the perspective of three paradigms: biological (rehabilitative), social and cultural.

From the perspective of a medical paradigm (rehabilitative), researchers focus on improvement of the level of functioning of a person with disabilities, whereas the determinant of integration is the efficiency of the process of social adaptation. Such efficiency is measured most frequently, often in combination with individual features of a person. An example is a paper with a telling title in the context of the phenomenon of integration "Szansa na społeczną akceptację" ("Chance for Social Acceptance"), where in the introduction the author does not declare own paradigmatic standpoint, but makes a straightforward claim:

"Personal functioning can be determined as adequate or not. This means that it either adheres to the applicable standards, principles and customs in a given society or not. Adequate also means that it allows for acceptance in a given society."

(Otrębski, 1997, p. 12)

The consequences of adopting such standpoint reflect what the author is examining and the claims that he/she is making. I do not assess the quality of such studies; I only wish to indicate that for the process of integration from this perspective, the level of social acceptance towards a person with disability and his/ ++her capacity to fulfil the requirements that are set, become the most important. Such assumption obviously has a series of theoretical and research consequences, determining both the perception of integration as a whole, as well as the directions of studies in this respect. The tasks of special education are defined in therapeutic categories such as improvement, correction or compensation of deficiencies. Some of the studies of this type are used to design social, occupational and rehabilitative policies for persons with disabilities, where integration becomes a goal for such activities.

Another perspective is offered by the social paradigm, which transfers the burden of liability for integration 
on the determinants of social relations among fully able and disabled persons. Models in this paradigm draw attention to the social structure of disability, stigmatising manifestations of discrimination and social oppression of otherness (cf. Rzeźnicka-Krupa, 2019). The fact of social isolation leads to the construction of social inclusion integration models, among them a number of educational solutions proposing various forms of joint education. From this perspective, integration is an opportunity for a disabled person, which has to be provided to guarantee correct functioning. However, it does not mean that the social paradigm (as many of its advocates seem to forget) is deprived of oppression with respect to a disabled person. It is simply transferred from the level of individual deficits to the level of social constructs of disability.

On the other hand, integration from the perspective of a cultural paradigm may be fully perceived as a form of oppression of the dominant culture, as a situation of appropriation of disability by normalcy. In this vision, integration activities have a colonising nature, and the mandatory educational integration is the best confirmation of it.

Modern studies on the process of integration are carried out in each of these three paradigms. A critical analysis and ability to define them is not aimed at determining which of them are the most valuable, but only at becoming aware of the differences in such perspectives, especially when one of them may be used for construction of our own project.

\section{RECAPITULATION}

Adequate paradigmatic awareness is indispensable in the modern pedagogy at least due to three reasons. First of all, it facilitates understanding of other researchers and reduces the consequences of failing to understand them. In particular in social sciences, the researcher has to account for the socio-cultural contexts of studies and the mode of their interpretation, especially when they were carried out several decades ago. Secondly, it allows for designating own perspective of the examined phenomenon through adequate paradigmatic discipline. Thus, the probability that our work will be correctly read and understood by others is growing. Thirdly, paradigmatic awareness makes it easier for us to analyse works as part of a scientific discourse. When defining a paradigm in the analysed work (or its absence), we may not only understand it better, but also criticise it. In some cases, upon exercising greater paradigmatic acuity, what origi- nally seemed a reasonable research intention may turn out to be a worthless combination of assumptions, data and unauthorised interpretations. A critical analysis may not only allow us to unmask thoughtless "transition of knowledge" (theses, concepts and theories) among individual paradigms, but it may also prevent the creation of such knowledge.

\section{ACKNOWLEDGEMENT}

None.

DISCLOSURE STATEMENT

No potential conflict of interest

was reported by the authors.

FUNDING: None. 


\section{REFERENCES}

Bauman Z. (1995). Modernity and Ambivalence, Cambridge.

Goffman E. (1975). Stigma. Frankfurt.

Foucault, M. (1975). Discipline and Punish: The Birth of the Prison, New York.

Freire P. (1970). Pedagogy of the Oppressed, New York.

Kuhn T. (1962). The Structure of Scientific Revolutions, University of Chicago Press, Chicago.

Kuhn T. (2003). Droga po strukturze. Eseje filozoficzne z 1970-1993, Warsaw.

Kuhn T. (2001). Struktura rewolucji naukowych, Warsaw.

Kuhn T. (2001). Postscriptum. Struktura rewolucji naukowych, Warsaw 2001, pp. 304-310.

Klus -Stańska D. (2018). Paradygmaty dydaktyki, myśleć teorią o praktyce, Warsaw 2018, p. 38.

Korczyński M. (2009). Wartości w przystosowaniu osób niepełnosprawnych, Lublin.

Krause A. (2014). Pedagogika w zmianie paradygmatycznej. Studia Edukacyjne No. 33/2014.

Masterman M. (1970). The Nature of Paradigm. I. Lakatos, A.E. Musgrave (ed.) Criticism and the Growth of Knowledge,

Cambridge University Press, Cambridge 1970, p. 59.

Obuchowska I. (1987). Obecne i nieobecne paradygmaty w pedagogice specjalnej. Kwartalnik Pedagogiczny 1987 No. 4, p. 29.

Otrębski W. (1997). Szansa na społeczną akceptację, Lublin, p. 12.

Rzeźnicka-Krupa J. (2019). Społeczne ontologie niepełnosprawności, ciało, tożsamość, performatywność. Kraków.

Stefańska A., (2018). Teatroterapia we wspomaganiu komunikacyjnym dorosłych osób z umiarkowaną niepełnosprawnością intelektualną, p. 105.

Śliwerski B. (2009). Współczesna myśl pedagogiczna, Znaczenia, klasyfikacje, badania. Kraków.

Twardowski A. (2004). Wokół wspomagania rozwoju - poszukiwanie terminologicznej jasności. Rewalidacja, No. 2, pp. 4-13. 